\title{
On-scene times for trauma patients in West Yorkshire
}

\author{
S W Goodacre, A Gray, A McGowan
}

\begin{abstract}
Objectives-To assess whether length of time on-scene in patients with major injury was associated with severity of injury or with abnormal on-scene physiology.

Methods-A retrospective analysis of a convenience sample of patients in whom prehospital on-scene times were entered onto the regional major trauma database. On-scene times of patients were analysed to assess whether ultimate injury severity score or on-scene physiology measurements affected times. This was undertaken by examining subgroups of patients with similar injury severity or physiological measurements by Wilcoxon-MannWhitney testing and comparing 95\% confidence intervals of the mean on-scene times.

Results-The mean on-scene time for 111 non-entrapped patients was 26 minutes (95\% confidence interval 23.5 to 28.6 ). Patients with injury severity score of $>15$, with a Glasgow coma scale of $<13$, and with an abnormal pulse spent significantly less time on-scene than less severely injured or physiologically deranged patients.

Conclusions-Paramedics have the ability to recognise patients with severe injury and reduce on-scene times. On-scene times were consistently long throughout all subgroups of major trauma patients. ( $($ Accid Emerg Med 1997;14:283-285)
\end{abstract}

Keywords: major injury; on-scene time; paramedic

The importance of early access to definitive care for patients with major injury is not in dispute $^{1}$ : short prehospital times have been associated with improved survival, ${ }^{23}$ while on-scene times of trauma victims have been extensively studied in the USA. ${ }^{45}$ Despite this there is still much controversy about how prehospital procedures or injury perception by paramedics affects prehospital times or benefits trauma patients. ${ }^{6-8}$ Several American studies have shown that paramedics are as good as formal trauma triage tools at identifying patients who may need trauma centre care. ${ }^{9}$ There are no published data on the decision making abilities of paramedics in the United Kingdom and little more on general prehospital trauma care by paramedics.

We studied on-scene times in a sample of trauma patients attended by paramedics in West Yorkshire in order to assess whether severity of injury and abnormal prehospital physiology affected on-scene times.

\section{Methods}

We studied a convenience sample of patients with major injury transported by paramedic staffed ambulances to Leeds General Infirmary (LGI) between January 1991 and July 1995. Injuries that fulfilled the major trauma outcome study (MTOS, UK) inclusion criteria were used as the study definition of major injury. A search was undertaken of all patients for whom on-scene times were recorded within this database. All prehospital data were originally recorded from paramedic report forms which are completed prospectively by the attending paramedic. Patients with no prehospital times recorded or transferred from elsewhere in the region were excluded.

Data for prehospital times, injury severity score (ISS), and on-scene physiology were extracted. Entrapment was said to occur if the paramedic had completed the relevant box on their report form for entrapment (extrication > 20 minutes).

Paramedic numbers were small during the study period and forms were only completed at the paramedic's discretion; this was usually only when a patient had received a prehospital paramedic procedure. An assessment was therefore made to compare the study sample's general characteristics against the main trauma database to determine whether it was representative. Age, sex, injury severity, and mortality were compared between the two groups:

Mean and median on-scene times were calculated for the entrapped and nonentrapped groups. The median was calculated to illustrate the possible effect of particularly long or short on-scene times on our results. The non-entrapped group were studied in greater detail in an attempt to identify variables that affected on-scene times significantly.

Patients were divided into three injury severity score bandings: ISS $1-15$, ISS $16-40$, and ISS $>40$. Ninety five per cent confidence intervals $(\mathrm{CI})$ of the mean on-scene times were then calculated for each subgroup. Confidence intervals were compared graphically to see if they overlapped. Statistical significance between related groups was assessed further by using a Wilcoxon-Mann-Whitney test.

\section{Results}

During the study period, 1433 trauma patients primarily attending Leeds General Infirmary and transported by ambulance (excluding 
Table 1 Study sample characteristics

\begin{tabular}{lllllll}
\hline & $\begin{array}{l}\text { Age range } \\
\text { (years) }\end{array}$ & $\begin{array}{l}\text { Mean age } \\
\text { (years) }\end{array}$ & $\begin{array}{l}\text { 95\% confidence intervals } \\
\text { of the mean }\end{array}$ & M:F & Median ISS & Mortality \\
\hline Study population & 3 to 90 & 35 & 31 to 38 & $3: 1$ & 17 & $25 \%$ \\
Trauma database & 0 to 102 & 44 & 43 to 46 & $3: 2$ & 9 & $6.7 \%$ \\
\hline
\end{tabular}

ISS, injury severity score.

Table 2 Injury severity score versus on-scene time

\begin{tabular}{llllll}
\hline Injury severity score & $\begin{array}{l}\text { Number of } \\
\text { patients }\end{array}$ & $\begin{array}{l}\text { Mean on scene time } \\
\text { (min) }\end{array}$ & $\begin{array}{l}\text { 95\% confidence intervals of } \\
\text { the mean }\end{array}$ & Median (min) & $\begin{array}{l}\text { On-scene time range } \\
\text { (min) }\end{array}$ \\
\hline $1-15$ & 53 & 28.7 & 24.5 to 33 & 25 & 7 to 80 \\
$16-40$ & 31 & 20.6 & 16.9 to 23.2 & 20 & 8 to 44 \\
$>40$ & 15 & 22.3 & 17.4 to 27.1 & 22 & 8 to 39 \\
\hline
\end{tabular}

transfers) were entered onto the trauma database. Data on 128 patients were analysed.

The mean on-scene time for the 111 non-entrapped patients was 26 minutes (range 7 to 80 minutes; median 23 minutes; $95 \%$ CI 23.5 to 28.6 ). The 17 entrapped patients had a mean on-scene time of 46.8 minutes (range 30 to 78 minutes; $95 \%$ CI 39.6 to 53 ). The study sample's general characteristics are compared with the remaining trauma database population in table 1 .

Tables 2 to 4 show results for on-scene times for injury severity scores, Glasgow coma scale (GCS), and pulse rate. There were insufficient data recorded to allow analysis of other physiological variables such as systolic blood pressure (recorded in 59 patients), respiratory rate (recorded in 32 patients), or the triage version of the revised trauma score (enough data in only 19 patients).

The on-scene times for patients with an ISS of 1-15 were compared with those with an ISS of 16-40 using a Wilcoxon-Mann-Whitney test. These were significantly different $(P=$ 0.0025). Significant differences were also found between patients with a GCS of 13-15 against a scale of less than $13(P=0.0003)$ and between patients with a pulse of 100 beats/min or more, or less than 50 beats $/ \mathrm{min}$, compared with a pulse rate of $50-99 / \mathrm{min}(P=0.0059)$. The differences in the $95 \%$ confidence intervals of the mean on-scene time of these groups are shown in tables 2 to 4 .

\section{Discussion}

Mean and median on-scene times in West Yorkshire for patients with major injury are long when compared with times from a review by Spaite et al of 43 studies from the USA and
Australia. ${ }^{10}$ Most of these studies are not directly comparable as they address only patients with penetrating trauma or patients with severe physiological derangement. Spaite's results suggest, however, that mean on-scene times can be reduced to less than 10 minutes with no reduction of advanced life support skills in patients with an ISS of $>15$.

The small amount of published work from the United Kingdom has revealed wide variation in on-scene times. Patients in Northern Ireland with an ISS of $>15$ had a mean on-scene time of 11.3 minutes. ${ }^{11}$ This mean on-scene time is considerably shorter than the mean time in our study of 20.6 minutes for patients with an ISS of 16-40. Results from a study from Plymouth showed mean on-scene times for patients with tibial shaft fractures varied from 17.1 to 37.5 minutes, depending on whether prehospital intravenous analgesia was given. ${ }^{12}$ A third study from Cornwall measured median on-scene times for compound lower limb fractures as 28 minutes. ${ }^{13}$ This time is similar to patients with an ISS of 1-15 in our study, who had a median on-scene time of 25 minutes.

Our results show that paramedics within West Yorkshire spend statistically less time on scene if the patient is more severely injured. This ability to triage has not previously been reported in the United Kingdom and contrasts with the findings of Rouse in Cornwall. ${ }^{13}$ In the USA it has been shown that paramedics can identify trauma patients who require trauma centre care as accurately as a number of formal prehospital triage tools. ${ }^{9}$ All subgroups in our study had mean and median on-scene times of 20 minutes or longer. This is more than twice as long as recommended by prehospital trauma

Table 3 Prehospital Glasgow coma score versus on-scene time

\begin{tabular}{llllll}
\hline $\begin{array}{l}\text { Glasgow coma } \\
\text { score }\end{array}$ & $\begin{array}{l}\text { Number of } \\
\text { patients }\end{array}$ & $\begin{array}{l}\text { Mean on scene time } \\
\text { (min) }\end{array}$ & $\begin{array}{l}95 \% \text { confidence intervals of } \\
\text { the mean }\end{array}$ & Median (min) & $\begin{array}{l}\text { On-scene time range } \\
\text { (minutes) }\end{array}$ \\
\hline $13-15$ & 59 & 29.5 & 26 to 33.1 & 27 & 9 to 73 \\
$3-12$ & 41 & 21.5 & 18 to 24.9 & 20 & 8 to 63 \\
\hline
\end{tabular}

Table 4 Prehospital pulse rate versus on-scene time

\begin{tabular}{llllll}
\hline $\begin{array}{l}\text { Pulse } \\
\text { (beats/min) }\end{array}$ & $\begin{array}{l}\text { Number of } \\
\text { patients }\end{array}$ & $\begin{array}{l}\text { Mean on scene time } \\
\text { (min) }\end{array}$ & $\begin{array}{l}95 \% \text { confidence intervals of } \\
\text { the mean }\end{array}$ & Median (min) & $\begin{array}{l}\text { On-scene time range } \\
\text { (min) }\end{array}$ \\
\hline $50-99$ & 47 & 30.6 & 25.9 to 35.3 & 25 & 7 to 80 \\
$>99$ or $<50$ & 47 & 22.3 & 19.3 to 25.3 & 21 & 8 to 50 \\
\hline
\end{tabular}


life support (PHTLS) teaching and by local paramedic codes of practice when transportation time is less than 10 minutes (mean on-scene time in this study was 23.4 minutes if transportation time was less than $10 \mathrm{~min}$ utes). ${ }^{14}$

Lastly prehospital data collection is poor and has to be improved before valid conclusions can be drawn on the value and effect of paramedic procedures on overall care in the United Kingdom. There were prehospital times available in only a small proportion of patients fulfilling our study criteria. A significant proportion of these patients had incomplete documentation of on-scene physiology.

The validity of this study is restricted because of the small number of patients with complete data. The results in table 1 , however, show that the study sample is younger, more severely injured, and with a much higher mortality than the main trauma database patients. This is the group of patients that should be spending the shortest time possible on-scene before definitive care. There is clearly a need for prospective study and improved data collection before the benefits of paramedic care in the United Kingdom can be assessed objectively. Unfortunately at present these are the best available data.

Recent years have seen increased awareness that on-scene times are too long and there is a move towards improving this aspect of paramedic care by running PHTLS-type teaching. National figures for the United Kingdom show that $21 \%$ of patients with severe injury (ISS > 15) do not reach hospital within one hour of injury. ${ }^{15}$ Prolonged on-scene times contribute to delay in providing definitive care and may therefore be associated with increase morbidity and mortality. ${ }^{9}$ We have, however, found evidence that paramedics can successfully recognise the seriously injured patient at scene and shorten on-scene times. Increased awareness of the benefits of short on-scene times and audit within ambulance training will reinforce the need for paramedics to act on their assessment and expedite transport to definitive care.

1 Trunkey DD. Trauma. Sci Am 1983;249:20-7.

2 Sampalis JS, Lavoie A, Williams JI, Mulder DS, Kalina M. Impact of on-site care, prehospital time, and the level of in-hospital care on survival in severely injured patients. J Trauma 1993;34:252-61.

3 Feero S, Hedges JR, Simmons E, Irwin L. Does out-ofhospital time affect trauma survival? Am J Emerg Med 1995;13:133-5.

4 Hedges JR, Feero S, Moore B, Shultz B, Haver DW. Factors contributing to paramedic on scene time during evaluation contributing to paramedic on scene time during evaluation and manage

5 Spaite DW, Valenzuela TD, Meislin HW, Criss EA, Hinsberg P. Prospective validation of a new model for evaluating emergency medical services systems by in-field observation of specific time intervals in prehospital care. Ann Emerg Med 1992;22:638-45.

6 Jacobs LM, Sinclair A, Beiser RB, D'Agostino RB. Prehospital advanced life support: benefits in trauma. J Trauma 1984;24:8-13

7 Smith PJ, Bodai BI, Hill AS, Frey CF. Prehospital stabilization of critically injured patients: a failed concept. J Trauma 1985;25:65-70

8 Bickell WH, Wall MJ, Pepe PE, Martin RR, Ginger VF, Allen $\mathrm{MK}$, et al. Immediate versus delayed fluid resuscitation for hypotensive patients with penetrating trauma. $\mathrm{N}$ Engl J Med 1994;331:1105-9.

9 Emerman CL, Shade B, Kubincanek J. A comparison of EMT judgement and prehospital triage instruments. J Trauma 1991;31:1369-75.

10 Spaite DW, Tse DJ, Valenzuala TD, Criss EA, Meislin HW, Mahoney $M$, et al. The impact of injury severity and prehospital procedures on scene times in victims of major prehospital procedures on scene times in victim

11 McNicholl BP. The golden hour and prehospital care. Injury 1994;25:251-4.

12 Johnson G, Guly HR. The effect of pre-hospital administration of intravenous nalbuphine on on-scene times. J Accid Emerg Med 1995;12:20-2.

13 Rouse A. Do ambulance crews triage trauma patients? Arch Emerg Med 1991;8:185-91.

14 Patient assessment and management. In: Pre-hospital trauma life support manual, 3rd ed. New York: Mosby Lifeline, 1994:52-71.

15 Yates DW, Woodford M, Hollis S. Preliminary analysis of the care of injured patients in 33 British hospitals: first the care of injured patients in 33 British hospitals: first study. BMJ 1992;305:737-40. 